\title{
Potent Inhibition of Biphasic Tubular Reabsorption of Lithium by Acetazolamide and Foscarnet in Rats
}

\author{
Yuichi UWAI ${ }^{1}$, Ryota KONDO ${ }^{1}$, Takato SUZUKI ${ }^{1}$, Tatsuya KAWASAKI ${ }^{1}$, Tomohiro \\ NABEKURA ${ }^{1}$
}

${ }^{1}$ Department of Pharmaceutics, School of Pharmacy, Aichi Gakuin University, Nagoya, Japan

Received August 20, 2019

Accepted December 11, 2019

Epub Ahead of Print June 25, 2020

\begin{abstract}
Summary
Lithium is mainly excreted into urine, and a large fraction of lithium filtered through glomeruli is reabsorbed in the proximal tubule. However, the mechanisms responsible for lithium reabsorption remain unclear. We previously reported that the reabsorption of lithium was biphasic in rats, and that foscarnet inhibited lithium reabsorption with a high affinity type. We herein evaluated the effects of acetazolamide and foscarnet on the renal excretion of lithium in rats treated with lithium chloride at 2 doses. In rats intravenously injected with a bolus of $25 \mathrm{mg} / \mathrm{kg}$ lithium chloride, acetazolamide facilitated the urinary excretion of lithium, and increased the fractional excretion of lithium from 0.446 to 0.953 , near the theoretically maximum value. At a dose of $2.5 \mathrm{mg} / \mathrm{kg}$ lithium chloride, the fractional excretion of lithium was 0.241 in control rats, 0.420 in rats administered acetazolamide, and 0.976 in rats administered acetazolamide and foscarnet. These results showed the potent inhibition of lithium reabsorption by acetazolamide and foscarnet in rats. And, it was exhibited that the effects of acetazolamide on lithium reabsorption differed with the dosages of lithium administered.
\end{abstract}

\section{Key words}

Lithium • Reabsorption • Acetazolamide • Foscarnet • Rat

\section{Corresponding author}

Yuichi Uwai, Department of Pharmaceutics, School of Pharmacy, Aichi Gakuin University, 1-100, Kusumoto, Chikusa, Nagoya, 464-8650 Japan. E-mail: yuuwai@dpc.agu.ac.jp

\section{Introduction}

Lithium is used in the treatment of bipolar disorder and is orally administered as lithium carbonate. The therapeutic range of lithium is narrow, and its plasma concentration is clinically monitored. Clinicians consider steady-state concentrations of 0.6 to $1.2 \mathrm{mEq} / 1$ to be optimal for the maintenance of bipolar disorder, and concentrations of 0.8 to $1.5 \mathrm{mEq} / \mathrm{l}$ as ideal for the acute management of manic episodes (Finley et al. 1995). When plasma lithium reaches toxic levels, the following symptoms are observed: lethargy, drowsiness, muscular weakness, nausea, diarrhea, confusion, dysarthria, nystagmus, ataxia, myoclonic twitches, increased deep tendon reflexes, seizures, syncope, and renal insufficiency (Finley et al. 1995).

Lithium has complete bioavailability and is mainly excreted into urine (Finley et al. 1995, Price et al. 1994). It does not bind to proteins in plasma (Price et al. 1994). The renal clearance of lithium $\left(\mathrm{Li} \mathrm{CL}_{\mathrm{r}}\right)$ is approximately $25 \%$ of creatinine clearance $\left(\mathrm{C}_{\mathrm{cr}}\right)$, which suggests that $75 \%$ of lithium filtered through the glomeruli is reabsorbed (Finley et al. 1995). The proximal tubule is the main site at which lithium is reabsorbed (Thomsen et al. 1968). Lithium interacts with furosemide, thiazide diuretics, angiotensin-converting enzyme inhibitors, and angiotensin II receptor antagonists during reabsorption (Finley et al. 1995, Finley 2016). And, the correlation coefficient between the clearance of lithium and creatinine is estimated to be 0.4548 with large interindividual differences in lithium reabsorption (Yukawa et al. 1993). The sodium-proton exchanger NHE3 has been a candidate mediating the reabsorption of lithium (Timmer et al. 1999), however, a complete understanding of the mechanisms responsible for lithium reabsorption remain unclear. We previously examined the effects of inhibitors of sodium-phosphate cotransporters 
and sodium-glucose cotransporters on the renal excretion of lithium in rats injected with a bolus of 3 or $2.5 \mathrm{mg} / \mathrm{kg}$ lithium chloride, and found that foscarnet and parathyroid hormone, inhibitors of sodium-phosphate cotransporters, facilitated the urinary excretion of lithium and increased $\mathrm{Li} \mathrm{CL}_{\mathrm{r}}$ and the fractional excretion of lithium, the ratio of Li $\mathrm{CL}_{\mathrm{r}}$ to $\mathrm{C}_{\mathrm{cr}}$ (Uwai et al. 2014, Uwai et al. 2018). The clearance of endogenous lithium was increased by parathyroid hormone in rats (Zhang et al. 1999). These findings suggested that foscarnet and parathyroid hormone inhibit the reabsorption of lithium in rats. Furthermore, we investigated dose dependency in lithium pharmacokinetics, and foscarnet had no effect in rats injected with $25 \mathrm{mg} / \mathrm{kg}$ lithium chloride (Uwai et al. 2018). At $25 \mathrm{mg} / \mathrm{kg}$ of lithium chloride, the fractional excretion of lithium was 0.441 . These findings implied that at least two types of transporters contribute to the tubular reabsorption of lithium in rats, and that sodiumphosphate cotransporters are involved in lithium reabsorption in rats administered lithium chloride at $2.5 \mathrm{mg} / \mathrm{kg}$.

Lithium intoxication is sometimes observed, and hemodialysis is one of the tools for its treatment (Gadallah et al. 1988). Lithium is quickly eliminated from plasma with hemodialysis, however, a rebound effect occurs as lithium in intracellular water equilibrates with extracellular fluid (Fenves et al. 1984). Continuous hemodiafiltration is another option (Leblanc et al. 1996), but requires a long time. The inhibition of lithium reabsorption is an effective strategy for lithium intoxication, and it is important to elucidate mechanisms of lithium reabsorption in the kidney and develop a strong inhibitor for lithium reabsorption. In the present study, we examined the inhibitory effects of acetazolamide on the reabsorption of lithium in rats intravenously injected with a bolus of 25 or $2.5 \mathrm{mg} / \mathrm{kg}$ lithium chloride. The response of the renal handling of lithium to acetazolamide was different from that to foscarnet.

\section{Materials}

Lithium chloride and mannitol were purchased from Wako Pure Chemical Industries (Osaka, Japan). Acetazolamide sodium (Diamox ${ }^{\circledR}$ ) was from Sanwa Kagaku Kenkyusho (Nagoya, Japan). Foscarnet sodium was from Cayman Chemical Company (Ann Arbor, MI, USA).
Pharmacokinetic experiments on lithium using rats intravenously injected with a bolus of lithium chloride

Lithium pharmacokinetic experiments were performed according to our previous study (Uwai et al. 2018). Animals were treated in accordance with the regulations of the Institutional Animal Use and Care Committee of the School of Pharmacy, Aichi Gakuin University. Seven-week-old male Wistar/ST rats were from Chubu Kagaku Shizai (Nagoya, Japan). Animals were caged for one or two days in an isolator with a 12-h light-dark cycle at $25^{\circ} \mathrm{C}$ in a room at the School of Pharmacy, Aichi Gakuin University. Rats were fed normal pellet food and water ad libitum. Under ethyl carbamate and $\alpha$-chloralose anesthesia, catheters were inserted into the femoral artery and femoral vein with polyethylene tubes (SP-31, Natsume Seisakusho, Tokyo, Japan) filled with heparin solution $(50 \mathrm{IU} / \mathrm{ml})$ for blood sampling and drug administration, respectively. Urine was collected from the urinary bladder catheterized with SP-31 polyethylene tubes.

To maintain a sufficient and constant urine flow, $5 \%$ mannitol in saline was infused at $0.03 \mathrm{ml} / \mathrm{min}$ until the last blood sampling after the injection of a $2.5 \mathrm{ml} / \mathrm{kg}$ bolus. Acetazolamide sodium at $1.1 \%$ and foscarnet sodium at $1.5 \%$ were coadministered with mannitol. Lithium chloride was dissolved in saline and was intravenously injected as a bolus at 25 or $2.5 \mathrm{mg} / \mathrm{kg}$, 20 minutes after the start of the mannitol infusion. Blood was collected $1,2,5,10,30$, and 60 minutes after the administration of lithium and centrifuged for plasma sampling. Bladder urine samples were collected from the administration of lithium to the last blood sampling.

After dilution with $0.1 \%$ nitric acid, the concentrations of lithium in plasma and urine were assessed using the atomic absorption spectrometry Agilent 280Z AA (Agilent Technologies, Santa Clara, CA, USA). The area under the plasma concentration-time curve of lithium until 60 minutes ( $\mathrm{Li} \mathrm{AUC}_{60}$ ) was calculated by the trapezoidal rule method. $\mathrm{Li} \mathrm{CL}_{\mathrm{r}}$ was obtained by dividing its urinary amount until 60 minutes after the lithium injection by $\mathrm{Li} \mathrm{AUC}_{60}$.

Creatinine concentrations in final bladder urine or plasma samples 60 minutes after the lithium injection were measured using the assay kit from Wako Pure Chemical Industries (Osaka, Japan). $\mathrm{C}_{\mathrm{cr}}$ was calculated by dividing its urinary excretion rate by the plasma concentrations of creatinine $\left(\mathrm{P}_{\mathrm{cr}}\right)$. The fractional excretion of lithium was assessed by dividing $\mathrm{Li} \mathrm{CL}_{\mathrm{r}}$ by $\mathrm{C}_{\mathrm{cr}}$. 
Statistical analysis

Data were expressed as the mean $\pm \mathrm{SE}$ and analyzed by an unpaired $t$-test or one-way analysis of variance followed by Scheffé's test using KaleidaGraph
(Synergy Software, Reading, PA, USA). Two-way repeated measures ANOVA was performed by using Prism (GraphPad Software, San Diego, CA, USA). Differences were considered to be significant at $P<0.05$.

Table 1. Pharmacokinetic parameters of lithium after intravenous injection of a bolus dose of $25 \mathrm{mg} / \mathrm{kg}$ lithium chloride in rats and the effects of acetazolamide.

\begin{tabular}{lcc}
\hline Parameter & Control & Acetazolamide \\
\hline$N$ & 8 & 8 \\
Weight $(\mathrm{g})$ & $211 \pm 1$ & $211 \pm 3$ \\
$P_{c r}(\mathrm{mg} / \mathrm{dl})$ & $0.594 \pm 0.020$ & $0.703 \pm 0.019^{* *}$ \\
$C_{c r}(\mathrm{ml} / \mathrm{min} / \mathrm{kg})$ & $3.76 \pm 0.16$ & $2.96 \pm 0.06^{* * *}$ \\
$\mathrm{Li} \mathrm{AUC}$ & & $52.0 \pm 1.1^{* * *}$ \\
$\mathrm{Li}$ CL $(\mathrm{mEq} \cdot \mathrm{min} / \mathrm{l})$ & $66.2 \pm 1.8$ & $2.81 \pm 0.09^{* * *}$ \\
Fractional $/ \mathrm{kg})$ & $1.66 \pm 0.11$ & $0.953 \pm 0.031^{* * *}$ \\
\hline
\end{tabular}

Each parameter represents the mean $\pm \mathrm{SE} .{ }^{* *} P<0.01,{ }^{* * *} P<0.001$, vs the control group.

Table 2. Pharmacokinetic parameters of lithium after intravenous injection of a bolus dose of $2.5 \mathrm{mg} / \mathrm{kg}$ lithium chloride in rats and the effects of acetazolamide and foscarnet.

\begin{tabular}{|c|c|c|c|}
\hline Parameter & Control & Acetazolamide & Acetazolamide and foscarnet \\
\hline$N$ & 8 & 8 & 8 \\
\hline Weight $(g)$ & $209 \pm 2$ & $209 \pm 3$ & $208 \pm 2$ \\
\hline$P_{c r}(m g / d l)$ & $0.506 \pm 0.012$ & $0.528 \pm 0.023$ & $0.485 \pm 0.019$ \\
\hline$C_{c r}(\mathrm{ml} / \mathrm{min} / \mathrm{kg})$ & $3.46 \pm 0.32$ & $3.25 \pm 0.15$ & $3.40 \pm 0.22$ \\
\hline $\operatorname{Li} A U C_{60}(\mathrm{mEq} \cdot \mathrm{min} / \mathrm{l})$ & $8.16 \pm 0.29$ & $8.20 \pm 0.39$ & $6.11 \pm 0.30^{* *}, \dagger \dagger$ \\
\hline $\mathrm{LiCL}(\mathrm{ml} / \mathrm{min} / \mathrm{kg})$ & $0.788 \pm 0.041$ & $1.37 \pm 0.14$ & $3.19 \pm 0.29^{* * *, \dagger \dagger}$ \\
\hline Fractional excretion of $L i$ & $0.241 \pm 0.022$ & $0.420 \pm 0.032$ & $0.976 \pm 0.117^{* * *, \dagger \dagger}$ \\
\hline
\end{tabular}

Each parameter represents the mean \pm SE. ${ }^{* *} P<0.01,{ }^{* * *} P<0.001$, vs the control group. ${ }^{+\dagger \dagger} P<0.001$, vs the acetazolamide group.

\section{Results}

Effects of acetazolamide on the renal excretion of lithium after the intravenous injection of a bolus of $25 \mathrm{mg} / \mathrm{kg}$ lithium chloride

The disposition of lithium after the injection of $25 \mathrm{mg} / \mathrm{kg}$ lithium chloride is shown in Fig. 1, and the pharmacokinetic parameters of lithium are summarized in Table 1. A significant reduction in the plasma concentration of lithium by acetazolamide was observed after 10, 30, and 60 minutes. In control rats, $18.6 \pm 1.2 \%$ (mean $\pm \mathrm{SE}$ ) of the lithium injected was excreted into urine until 60 minutes. Acetazolamide significantly increased this value up to $24.8 \pm 0.9 \%$. $\mathrm{Li} \mathrm{AUC}_{60}$ and $\mathrm{Li} \mathrm{CL}_{\mathrm{r}}$ were $66.2 \pm 1.8 \mathrm{mEq} \cdot \mathrm{min} / \mathrm{l}$ and $1.66 \pm$
$0.11 \mathrm{ml} / \mathrm{min} / \mathrm{kg}$, respectively, in the control group. Acetazolamide significantly decreased $\mathrm{Li} \mathrm{AUC}_{60}$ and increased $\mathrm{Li} \mathrm{CL}$. The fractional excretion of lithium was calculated as $0.446 \pm 0.029$ in control rats, and this value was increased to $0.953 \pm 0.031$ by acetazolamide $(P<0.001)$.

Effects of acetazolamide and foscarnet on the renal excretion of lithium after the intravenous injection of a bolus of $2.5 \mathrm{mg} / \mathrm{kg}$ lithium chloride

Fig. 2 shows the plasma concentration of lithium and its cumulative urinary excretion after the intravenous injection of $2.5 \mathrm{mg} / \mathrm{kg}$ lithium chloride. The pharmacokinetic parameters of lithium are shown in Table 2. The plasma concentrations of lithium were similar in the acetazolamide and control groups. 
a

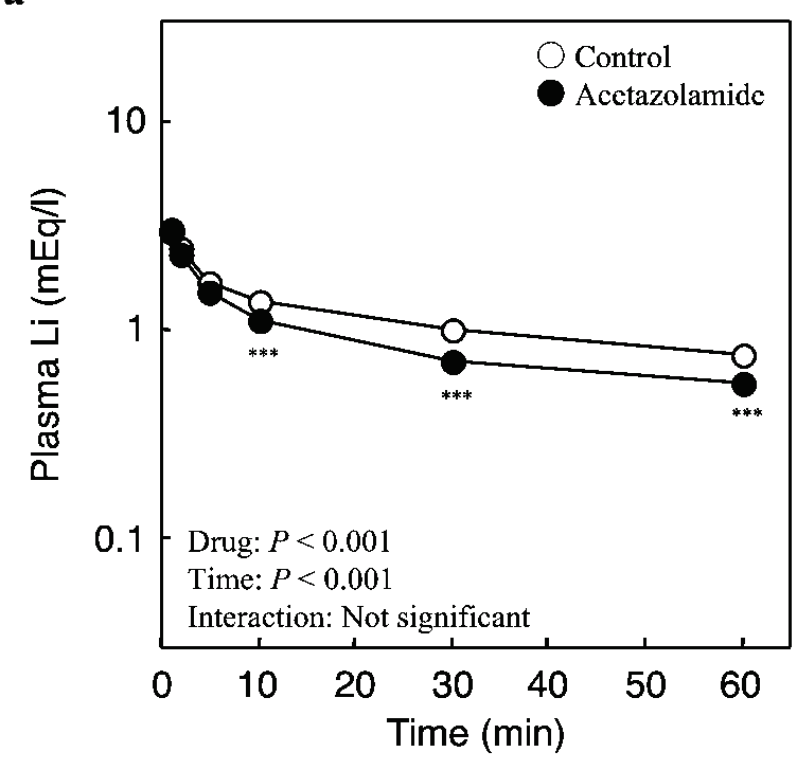

b

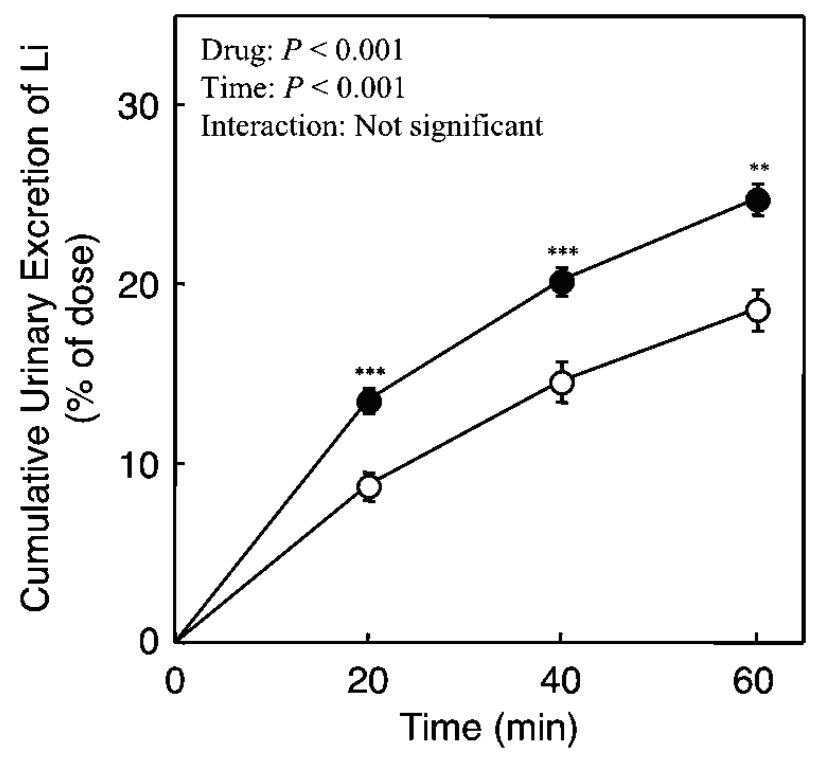

Fig. 1. Effects of acetazolamide on the plasma concentration (a) and urinary excretion (b) of lithium after the intravenous injection of a bolus of $25 \mathrm{mg} / \mathrm{kg}$ lithium chloride in rats. Mannitol at $5 \%$ in the absence (control, open circle) or presence of $1.1 \%$ acetazolamide sodium (closed circle) was infused at $0.03 \mathrm{ml} / \mathrm{min}$ after the instantaneous injection of $2.5 \mathrm{ml} / \mathrm{kg}$ via the femoral vein. Twenty minutes after the mannitol injection, a bolus of $25 \mathrm{mg} / \mathrm{kg}$ lithium chloride was intravenously injected. (a) Lithium concentrations in plasma at the indicated times after the injection were measured. (b) Urine samples at intervals of 20 minutes were collected until $60 \mathrm{~min}$ after the lithium injection. Lithium concentrations in bladder urine were measured, and the cumulative amounts excreted into urine were calculated. Each point represents the mean \pm SE of 8 rats. ${ }^{* *} P<0.01,{ }^{* * *} P<0.001$, vs the control group. Results from two-way repeated measures ANOVA are shown inside the graphs.

Li $\mathrm{AUC}_{60}$ was significantly lower in the acetazolamide and foscarnet group than in the other groups. In the control group, $10.8 \pm 0.5 \%$ of the lithium administered was recovered into urine after 60 minutes. Acetazolamide significantly increased the urinary excreted amount of lithium to $18.6 \pm 1.3 \%$. Acetazolamide increased $\mathrm{Li} \mathrm{CL}_{\mathrm{r}}$ from $0.788 \pm 0.041 \mathrm{ml} / \mathrm{min} / \mathrm{kg}$ to $1.37 \pm 0.14 \mathrm{ml} / \mathrm{min} / \mathrm{kg}$, however, no significant difference was observed. The coadministration of acetazolamide and foscarnet further facilitated the urinary excretion of lithium. $\mathrm{Li} \mathrm{CL}_{\mathrm{r}}$ and the fractional excretion of lithium were $3.19 \pm$ $0.29 \mathrm{ml} / \mathrm{min} / \mathrm{kg}$ and $0.976 \pm 0.117$, respectively, which were significantly higher than those in the other groups.

\section{Discussion}

We examined the disposition of lithium in rats injected with a bolus of 25 or $2.5 \mathrm{mg} / \mathrm{kg}$ lithium chloride as well as the effects of acetazolamide. The experimental procedures employed were identical to those in our previous study, except for the administration of acetazolamide and foscarnet, and the pharmacokinetic parameters of lithium in each control group (Tables 1 and 2) were similar to the former values (Uwai et al. 2018). $\mathrm{Li} \mathrm{CL}_{\mathrm{r}}$ and the fractional excretion of lithium were significantly higher in control rats administered lithium chloride at $25 \mathrm{mg} / \mathrm{kg}$ than those in control rats administered $2.5 \mathrm{mg} / \mathrm{kg}(P<0.001$ for both by unpaired $t$-test). A non-linear disposition of lithium was observed, similar to that of our previous study (Uwai et al. 2018).

In rats intravenously injected with a bolus of $25 \mathrm{mg} / \mathrm{kg}$ lithium chloride, acetazolamide decreased $\mathrm{C}_{\mathrm{cr}}$, but facilitated the urinary excretion of lithium and increased $\mathrm{Li} \mathrm{CL}_{\mathrm{r}}$ (Table 1 and Fig. 1b). Acetazolamide also increased the fractional excretion of lithium from 0.446 to 0.953 in rats (Table 1). Lithium does not bind to proteins in plasma, and tubular secretion has not been shown to contribute to the renal excretion of lithium. Therefore, when the reabsorption of lithium is completely inhibited, the fractional excretion of lithium is one, theoretically at the maximum. Our result demonstrated the strong inhibition of lithium reabsorption by acetazolamide. Other laboratories reported that acetazolamide incremented the fractional excretion of lithium in rats, but the values did not reach 0.6 (Fransen et al. 1993, Steele et al., 1976). The infusion rate of acetazolamide in our study was more than 4 times those of their studies. To our knowledge, this study is the first to show the maximum elevation in the fractional excretion of lithium.

In rats injected with lithium chloride at $2.5 \mathrm{mg} / \mathrm{kg}$, acetazolamide facilitated the renal excretion of lithium (Fig. 2b). However, the increases in $\mathrm{Li} \mathrm{CL}_{\mathrm{r}}$ and 
$\mathbf{a}$

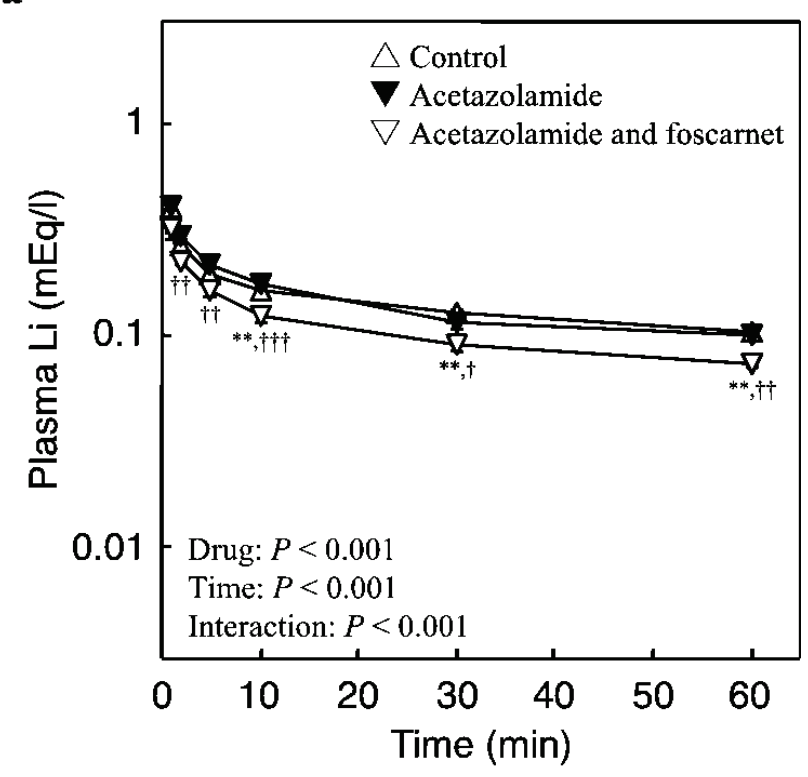

b

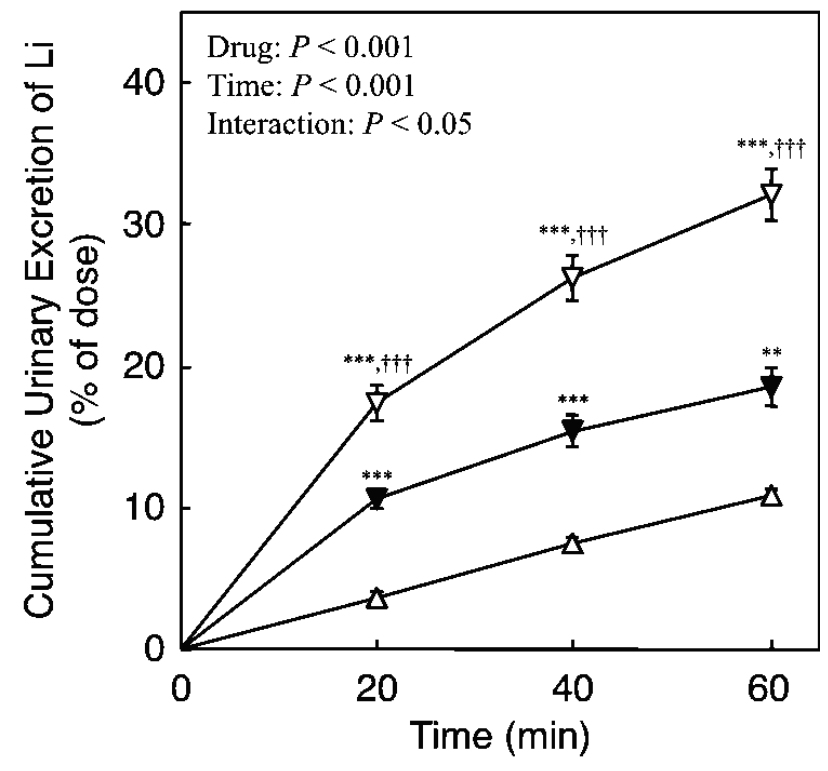

Fig. 2. Effects of acetazolamide and foscarnet on the plasma concentration (a) and urinary excretion (b) of lithium after the intravenous injection of a bolus of $2.5 \mathrm{mg} / \mathrm{kg}$ lithium chloride in rats. Mannitol at $5 \%$ in the absence (control, open up-pointing triangle) or presence of $1.1 \%$ acetazolamide sodium only (closed triangle) or $1.1 \%$ acetazolamide sodium with $1.5 \%$ foscarnet sodium (down-pointing triangle) was infused at $0.03 \mathrm{ml} / \mathrm{min}$ after the instantaneous injection of $2.5 \mathrm{ml} / \mathrm{kg}$ via the femoral vein. Twenty minutes after the mannitol injection, a bolus of $2.5 \mathrm{mg} / \mathrm{kg}$ lithium chloride was intravenously injected. (a) Lithium concentrations in plasma at the indicated times after the injection were measured. (b) Urine samples at intervals of 20 minutes were collected until $60 \mathrm{~min}$ after the lithium injection. Lithium concentrations in bladder urine were measured, and the cumulative amounts excreted into urine were calculated. Each point represents the mean $\pm \mathrm{SE}$ of 8 rats. ${ }^{* *} P<0.01,{ }^{* * *} P<0.001$, vs the control. ${ }^{+} P<0.05,{ }^{+\dagger} P<0.01,{ }^{++\dagger} P<0.001$, vs the acetazolamide group. Results from two-way repeated measures ANOVA are shown inside the graphs. the fractional excretion of lithium caused by acetazolamide were not significant (Table 2). The effects of acetazolamide on the fractional excretion of lithium differed with the dosages of lithium administered (Tables 1 and 2). We previously observed the opposite phenomenon in rats administered foscarnet. Foscarnet facilitated the urinary excretion of lithium and increased Li $\mathrm{CL}_{\mathrm{r}}$ and its fractional excretion in rats administered $2.5 \mathrm{mg} / \mathrm{kg}$ lithium chloride, whereas no effect of foscarnet was observed when $25 \mathrm{mg} / \mathrm{kg}$ lithium chloride was injected (Uwai et al. 2018). As shown in Fig. 2b, the amount of lithium excreted into urine in rats administered both acetazolamide and foscarnet was markedly higher than that of rats receiving acetazolamide alone. As a result, the coadministration of acetazolamide and foscarnet significantly increased $\mathrm{Li} \mathrm{CL}_{\mathrm{r}}$ from the value in rats receiving acetazolamide alone (Table 2). The fractional excretion of lithium was increased to 0.976 , the maximum level, by the coadministration of acetazolamide and foscarnet (Table 2), implying the complete inhibition of lithium reabsorption. These results suggest that sodium-phosphate cotransporter(s) and acetazolamideinhibitable transporter reabsorbed lithium, and that the role of the former was greater in that concentration range. Taken together with the results obtained in rats injected with a bolus of $25 \mathrm{mg} / \mathrm{kg}$ lithium chloride, a low-affinity acetazolamide-inhibitable transporter and high-affinity sodium-phosphate cotransporter(s) appear to be involved in the reabsorption of lithium in the rat kidney.

In the present study, after acetazolamide sodium was intravenously injected as a bolus at $27.5 \mathrm{mg} / \mathrm{kg}$, it was infused into the vein at $0.33 \mathrm{mg} / \mathrm{min}$. The instantaneously injected dose of acetazolamide sodium was more than twice the clinical dose. Furthermore, the clinical dose of foscarnet is less than half of the dose administered in the present study. Accordingly, the strong inhibition of lithium reabsorption by acetazolamide and foscarnet may not have occurred at clinical situation.

The molecular mechanism of the lithium reabsorption has not been fully elucidated, and only epithelial sodium channel $\mathrm{ENaC}$ located in the brushborder membrane of collecting duct was shown to mediate lithium uptake into principal cells by in vitro experiment (Kortenoeven et al. 2009). And, acetazolamide inhibited lithium uptake by $\mathrm{ENaC}$ (de Groot et al. 2016). The ATP/UTP/P2Y 2 receptor system regulates $\mathrm{ENaC}$ (Vallon et al. 2011), and may be involved in the inhibition of $\mathrm{ENaC}$ by acetazolamide. The findings may be related, in part, to the lithium- 
acetazolamide interaction. NHE3 has been a candidate transporter that reabsorbs lithium in the kidney (Timmer et al. 1999). Because acetazolamide was shown to inhibit the function of NHE3 (Krishnan et al. 2015), we conducted this study. Recently, it has been reported that the knockout of NHE3 had no effect on the pharmacokinetics of lithium (Thomas et al. 2019). We wonder whether it has not yet been shown that a known transporter is inhibited by acetazolmide or an unidentified transporter contributes to the lithium reabsorption.

In the proximal tubule, sodium-dependent phosphate transporters NaPi-IIa (SLC34A1), NaPi-IIc (SLC34A3), and PiT-2 (SLC20A2) mediate the reabsorption of phosphate filtered through the glomeruli (Biber et al. 2013). It was shown that the three phosphate transporters were inhibited by foscarnet (Forster et al. 1998, Ghezzi et al. 2009, Villa-Bellosta et al. 2007). Accordingly, it is difficult to identify the transporter responsible for the lithium reabsorption among them by using foscarnet.
In conclusion, we herein demonstrated that biphasic lithium reabsorption in the rat kidney was potently inhibited using acetazolamide and foscarnet. Our previous study represented that the effects of foscarnet on the fractional excretion of lithium differed with the dosages of lithium administered (Uwai et al. 2018), and this study showed that acetazolamide filled the hole of foscarnet regarding the inhibition of lithium reabsorption. These results provide fundamental information for better understanding of lithium reabsorption in the kidney and development of a strong inhibitor for lithium reabsorption in patients with lithium intoxication.

\section{Conflict of Interest}

There is no conflict of interest.

\section{Acknowledgements}

This work was supported by a Grant-in-Aid for Scientific Research from the Japan Society for the Promotion of Science (Grant no. 16K08419).

\section{References}

BIBER J, HERNANDO N, FORSTER I: Phosphate transporters and their function. Annu Rev Physiol 75: 535-550, 2013. https://doi.org/10.1146/annurev-physiol-030212-183748

DE GROOT T, SINKE AP, KORTENOEVEN ML, ALSADY M, BAUMGARTEN R, DEVUYST O, LOFFING J, WETZELS JF, DEEN PM: Acetazolamide attenuates lithium-induced nephrogenic diabetes insipidus. J Am Soc Nephrol 27: 2082-2091, 2016. https://doi.org/10.1681/ASN.2015070796

FENVES AZ, EMMETT M, WHITE MG: Lithium intoxication associated with acute renal failure. South Med J 77 : 1472-1474, 1984. https://doi.org/10.1097/00007611-198411000-00030

FINLEY PR: Drug interactions with lithium: an update. Clin Pharmacokinet 55: 925-941, 2016. https://doi.org/10.1007/s40262-016-0370-y

FINLEY PR, WARNER MD, PEABODY CA: Clinical relevance of drug interactions with lithium. Clin Pharmacokinet 29: 172-191, 1995. https://doi.org/10.2165/00003088-199529030-00004

FORSTER I, HERNANDO N, BIBER J, MURER H: The voltage dependence of a cloned mammalian renal type II $\mathrm{Na}^{+} / \mathrm{Pi}$ cotransporter (NaPi-2). J Gen Physiol 112: 1-18, 1998. https://doi.org/10.1085/jgp.112.1.1

FRANSEN R, BOER WH, BOER P, DORHOUT MEES EJ, KOOMANS HA: Effects of furosemide or acetazolamide infusion on renal handling of lithium: a micropuncture study in rats. Am J Physiol 264: R129-R134, 1993. https://doi.org/10.1152/ajpregu.1993.264.1.R129

GADALLAH MF, FEINSTEIN EI, MASSRY SG: Lithium intoxication: clinical course and therapeutic considerations. Miner Electrolyte Metab 14: 146-149, 1988.

GHEZZI C, MURER H, FORSTER IC: Substrate interactions of the electroneutral Na+-coupled inorganic phosphate cotransporter (NaPi-IIc). J Physiol 17: 4293-4307, 2009. https://doi.org/10.1113/jphysiol.2009.175596

KORTENOEVEN ML, LI Y, SHAW S, GAEGGELER HP, ROSSIER BC, WETZELS JF, DEEN PM: Amiloride blocks lithium entry through the sodium channel thereby attenuating the resultant nephrogenic diabetes insipidus. Kidney Int 76: 44-53, 2009. https://doi.org/10.1038/ki.2009.91

KRISHNAN D, LIU L, WIEBE SA, CASEY JR, CORDAT E, ALEXANDER RT: Carbonic anhydrase II binds to and increases the activity of the epithelial sodium-proton exchanger, NHE3. Am J Physiol Renal Physiol 309: F383-F392, 2015. https://doi.org/10.1152/ajprenal.00464.2014 
LEBLANC M, RAYMOND M, BONNARDEAUX A, ISENRING P, PICHETTE V, GEADAH D, QUIMET D, ETHIER J, CARDINAL J: Lithium poisoning treated by high-performance continuous arteriovenous and venovenous hemodiafiltration. Am J Kidney Dis 27: 365-372, 1996. https://doi.org/10.1016/S0272$\underline{6386(96) 90359-5}$

PRICE LH, HENINGER GR: Lithium in the treatment of mood disorders. N Engl J Med 331: 591-598, 1994. https://doi.org/10.1056/NEJM199409013310907

STEELE TH, DUDGEON KL, LARMORE CK: Pharmacological characterization of lithium reabsorption in the rat. J Pharmacol Exp Ther 196: 188-193, 1976.

THOMAS L, XUE J, DOMINGUEZ RIEG JA, RIEG T: Contribution of NHE3 and dietary phosphate to lithium pharmacokinetics. Eur J Pharm Sci 128: 1-7, 2019. https://doi.org/10.1016/j.ejps.2018.11.008

THOMSEN K, SCHOU M: Renal lithium excretion in man. Am J Physiol 215: 823-827, 1968. https://doi.org/10.1152/ajplegacy.1968.215.4.823

TIMMER RT, SANDS JM: Lithium intoxication. J Am Soc Nephrol 10: 666-674, 1999.

UWAI Y, ARIMA R, TAKATSU C, FURUTA R, KAWASAKI T, NABEKURA T: Sodium-phosphate cotransporter mediates reabsorption of lithium in rat kidney. Pharmacol Res 87: 94-98, 2014. https://doi.org/10.1016/j.phrs.2014.06.012

UWAI Y, KAWASAKI T, NABEKURA T: Nonlinear disposition of lithium in rats and saturation of its tubular reabsorption by the sodium-phosphate cotransporter as a cause. Biopharm Drug Dispos 39: 83-87, 2018. https://doi.org/10.1002/bdd.2116

VALLON V, RIEG T: Regulation of renal $\mathrm{NaCl}$ and water transport by the ATP/UTP/P2Y2 receptor system. Am J Physiol Renal Physiol 301: F463-F475, 2011. https://doi.org/10.1152/ajprenal.00236.2011

VILLA-BELLOSTA R, BOGAERT YE, LEVI M, SORRIBAS V: Characterization of phosphate transport in a rat vascular smooth muscle cells: implications for vascular calcification. Arterioscler Thromb Vasc Biol 27: 1030-1036, 2007. https://doi.org/10.1161/ATVBAHA.106.132266

YUKAWA E, NOMIYAMA N, HIGUCHI S, AOYAMA T: Lithium population pharmacokinetics from routine clinical data: role of patient characteristics for estimating dosing regimens. Ther Drug Monit 15: 75-82, 1993. https://doi.org/10.1097/00007691-199304000-00002

ZHANG Y, NORIAN JM, MAGYAR CE, HOLSTEIN-RATHLOU NH, MIRCHEFF AK, McDONOUGH AA: In vivo PTH provokes apical NHE3 and NaPi2 redistribution and Na-K-ATPase inhibition. Am J Physiol 276: F711-F719, 1999. https://doi.org/10.1152/ajprenal.1999.276.5.F711 